\title{
Preventing or inventing? Understanding the effects of non-prescriptive design briefs
}

\author{
Sonja Oliveira' ${ }^{1}$ Elena Marco ${ }^{1}$
}

Accepted: 3 May 2016/Published online: 13 May 2016

(C) The Author(s) 2016. This article is published with open access at Springerlink.com

\begin{abstract}
This paper discusses observations of an architecture and environmental engineering undergraduate design studio project assigned to 4th year students at a UK university. In the UK, most architecture courses are characterised by a high proportion of design studio teaching supported by varying amount of technical modules that include environmental and construction learning. Recent scholarship on sustainability education in architecture, discusses the necessity for new approaches that enhance transdisciplinarity, autonomy and independent decision-making. However, despite increasing importance to both practice and policy, few empirical or theoretical examples account for the implications or experiences of such an approach. This study presents the experiences of an architecture and environmental engineering design studio whereby studio activities are closely interlinked with technical engineering enquiry and experiment. Specifically, the research examines the challenges and opportunities students face when assigned a design project that attempts to translate independently derived briefs into novel architectural environmentally engineered interpretations. The analysis draws on a series of ethnographic narrative and visual observations carried over a period of 6 months. The implications of the findings are threefold. First, the analysis shows the opportunities an integrated crossdisciplinary approach can offer, where the gap between creative and technical domains is narrowed. Second, the study presents some of the challenges faced by increased autonomy and lack of prescription that students encounter. Third, the paper contributes to an emerging agenda of sustainability education in the built environment by offering valuable insights into the benefits and difficulties cross-disciplinary approaches pose to architectural education.
\end{abstract}

Keywords Architecture - Environmental engineering · Pedagogy · Sustainability · Design education

Sonja Oliveira

Sonja.Dragojlovic-Oliveira@uwe.ac.uk

1 Department of Architecture and the Built Environment, Faculty of Environment and Technology, University of the West of England, Bristol, UK 


\section{Introduction}

There is a growing awareness and need to implement sustainability education in architecture curricula. Educating future practitioners in the skills, competencies and design principles to respond to sustainability challenges is raised by many scholars as an 'emerging imperative' (Altomonte et al. 2012). However, attention is often focused on highlighting pedagogical barriers to successful implementation as well as suggesting methods for effective application. Barriers are seen to be related to long established and ingrained pedagogical techniques traditionally applied in design studio teaching viewed as distinct from other aspects of the curriculum (Coleman 2010). Also, the growing modularization of architecture curricula (Cotgrave and Kokkarinen 2011) and overly regulated prescription criteria (Cotgrave and Alkhaddar 2006) are viewed as potential stumbling blocks. In addition to problematizing sustainability practice in architecture education, an increasing number of scholars propose models to develop new non-prescriptive environmental pedagogical praxis (Iulo et al. 2013; Savic and Kashef 2013). Altomonte (2009, 2012) argues that established prescriptive design pedagogies impede student's creativity and personal development. He suggests a new sustainable paradigm of architectural education is needed to promote inter-and trans-disciplinary practice, independent learning and self-reflexivity (Altomonte et al. 2012).

Architecture education in the UK is monitored and validated by its professional bodies. Professional bodies such as Royal Institute of British Architects/Architectural Registration Board (RIBA/ARB) base criteria for prescription/validation of Part $1 / 2$ qualifications on the requirements of article 46 of the EU Qualifications Directive (2005/36/EC). Curricula currently follow a three-part route, which is administered by the ARB in respect of the protected title of "architect". This route is also adopted by the RIBA as a condition of membership. Part 1 is usually undertaken through full-time undergraduate study of not $<3$ years. The syllabus covers five themes including design, communication, technology and environment, cultural context and management, practice and law with specific focus on developing students' awareness, knowledge and abilities (RIBA 2003). Although RIBA advocates interdisciplinary teaching and holistic approaches to teaching, few universities in the UK currently implement dual accreditation or formal transdisciplinary course structures.

In addition, although research has articulated where challenges and difficulties lie, few studies have documented the effects of implementing some of the possible suggested solutions or improvements. The purpose of this paper is to examine the effects of implementing a non-prescriptive brief in a design studio architecture and environmental engineering module at a UK university. The research asks the question of how students experience, discuss and represent sustainability issues when given a non-prescriptive brief within a highly integrated transdisciplinary course structure accredited by RIBA and CIBSE. The following sections discuss relevant literatures on sustainability education in design studio settings and architecture curricula more broadly. It is followed by an outline of the research setting and method. Following on the findings section, the discussion and conclusion outline key implications and contributions of the research.

\section{Literature review}

Scholars focus on several aspects relating to sustainability education in architecture and associated built environment curricula: barriers to implementation (Cotgrave and Alkhaddar 2006; Murray and Cotgrave 2007; Pan et al. 2012; Peel 2010, 2012) and 
guidance on how to achieve effective integration (Batterman et al. 2011; Iulo et al. 2013; Savic and Kashef 2013). Pan et al. (2012) argue barriers to successful implementation of sustainability education are found in conflicting approaches to research versus teaching amongst students, lecturers and the institutions. Cotgrave and Alkhaddar (2006) also outline barriers to achieving environmental literacy in the wider construction education sector including architecture courses. Limitations are described as being contained within the nature and structure of higher education in the UK in areas such as academic indifference and approaches to teaching, lack of communication between industry and academia and lack of student engagement (Cotgrave and Alkhaddar 2006). Cotgrave and Kokkarinen (2011) undertook a comparative study examining the impact of curriculum design on sustainability pedagogy. Their study highlights a lack of consistency between how sustainability is taught and how it is applied in the design studio. The findings for their study suggest that the divergence between sustainability teaching and application could be partially attributed to growing modularisation in the curriculum within UK higher education, resulting in disjointed learning outcomes.

Similarly, O'Rafferty et al. (2014) analyse the challenges of mainstreaming sustainable design education across design disciplines suggesting an 'overcrowded curriculum' (2014, p. 173) reduces the capacity for environmental literacy. They highlight how future practitioners will require skills in 'eco-design, sustainable innovation and responsible design' (2014, p. 171). Cotgrave and Kokkarinen (2011) suggest that the integration of sustainability in construction related curricula is not limited purely to teaching design principles, but rather about embedding the values of sustainability. Altomonte et al. (2012) suggest deficiencies lie at a European level in university architectural education curriculum set ups. They explore the outcomes of a European project 'Environmental Design in University Curricula and Architectural Training in Europe (EDUCATE), suggesting barriers to implementing sustainability in architectural education lie in educational policy and organizational barriers at a strategic European level.

In addition to documenting disconnects between taught lectures and the design studio, scholars discuss the role of academic staff in embedding sustainability education in design studio pedagogy. Cotgrave and Kokkarinen (2011) describe a lack of enthusiasm for sustainability from academic staff and report that in many institutions teaching staff lack specific expertise in environmental design. Furthermore, they suggest that there is a certain level of unwillingness for teaching staff to increase their sustainable design knowledge, which they attribute to being unable or reluctant to increase expertise outside of their specialist field. O'Rafferty et al. (2014) suggest that some educators may feel uncomfortable with the interdisciplinary demands of sustainable and environmental design principles.

A number of scholars focus on proposing methodologies for successfully integrating specific sustainability concerns into the curriculum. For instance, Batterman et al. (2011) review existing educational programs at 20 universities in Portugal identifying educational competencies in the area of energy and sustainability in the built environment. Their study proposes model competencies for two EfS specialties including "Buildings and Urban Environments" and "Energy Systems and Policy". Competencies are ranked through a set of priorities and applied in the development of a multidisciplinary masters and doctoral programs at the University of Coimbra. Iulo et al. (2013, p. 42) identify how sustainability challenges are complex and can only be addressed through 'interdisciplinary knowledge from natural sciences, humanities, social sciences, and the arts'. They advocate for courses to be taught jointly by different disciplines suggesting this could improve environmental literacy by gaining 'different perspectives on sustainable issues' (Iulo et al. 2013, p. 443). 
Rutherford and Wilson (2006, p. 267) suggest that teaching in the design studio should be better sequenced to enable lecture programmes to be tailored to design projects rather than 'peripheral to design studios'. Furthermore, they discuss how studio briefs should be designed to facilitate the application of environmental concepts learnt in lectures, recommending that 'brief flexibility' should be encouraged. O'Rafferty et al. (2014, p. 172) advocate 'lifecycle thinking' that encourages students to engage with the environmental challenges arising in all stages of the design process. They highlight how independent decision making, personal responsibility and individual creativity can be encouraged through a capacity building framework that aims to improve competencies in creativity, culture and values.

Although scholarship on sustainability in design education has not studied effects of design briefs or students' engagement on the topic in design studio, there is an emerging body of research that considers effects and use of design studio briefs on designers' outcomes. For many the process of interpreting and resolving a brief is viewed as 'framing' (Cross 2011; Lawson and Dorst 2013) defined as 'the ability to frame a problematic situation in new and interesting ways' (Paton and Dorst 2011). Schön (1988) discusses design as a process of framing a problem through reflection and iteration where the designer performs 'moves' towards finding a solution.

With the exception of emerging recent work in other design domains, there is limited empirical account of how architecture students experience and process a design brief and specifically the characteristics of 'moves' they perform to interpret a brief. Goldschmidt and Rogers (2013) studied industrial and architecture undergraduate students' responses to a design studio brief, finding that most students direct attention to proposing a product first irrespective of their design discipline. Their findings also reflect upon the need for flexibility in management of time constraints when students are faced with open-ended illdefined tasks. Paton and Dorst (2011) study the communication and language strategies professional designers adopt to reframe a client's brief in order to produce a more' workable' and 'actionable' frame (2011, p. 585). For Curry (2014) the emphasis is placed on educators being able to respond to individual needs of students' interpretation of briefs. Based on their particular brief responses specific design methodologies are proposed.

Discussions above demonstrate an awareness and willingness to engage in a pedagogical and professional shift in design related disciplines to understand the effects of design briefs. While research identifies the importance of understanding briefing (whether prescriptive or non-prescriptive), understanding the characteristics and mechanisms that design students employ to interpret briefs specifically in architecture education is poorly understood and largely overlooked.

Whilst there is a rich discussion that calls for increased opportunities for creativity, personal development and environmental literacy in architecture education, there is less discussion that considers the practical applications or the implications of such changes. Scholars have suggested a range of models and frameworks intended to assist this pedagogical shift, however, there is little consideration given to how these would be replicated across different institutions as a programme of delivery. Further research into these proposed changes would provide a richer understanding of the implications for teaching staff and course design and delivery, and the impact these proposed changes may have on the student experience.

\section{Research method and empirical setting}

The study employs an ethnographic approach reliant on narrative, observational and visual methods as advocated by Austerlitz (2007). Ethnographic research methods have become widely accepted, both inside and outside of the social sciences, as a tool for holistic enquiry 
and for gathering and collecting data in a naturalist research setting. Furthermore, ethnographers seek to make sense of phenomena by understanding the social and cultural systems that surround it. Austerlitz (2007) carried out an ethnographic study into the experiences of design students, which demonstrates how future research into design studio pedagogy could be carried out. His study was intended to provide 'insight to the students' world and into their perception of the educational process and outcomes' (Austerlitz 2007, p. 168). He describes the key advantages of an ethnographic approach as 'promoting understanding of the context of occurrences...enabling the researcher to observe occurrences in real time...creating a participant-researcher relationship of trust' (Austerlitz 2007, p. 172).

\section{Data collection}

The data collection and analysis in this study draws on Austerlitz's (2007) approach using narrative and visual methods. Narrative methods included talking to students and staff, observing design review discussions, workshops and assessments. Visual methods included use of sketches, photographs and drawings to record discussions. The first author was immersed in the studio talking to students, taking notes, sketching with them and observing assessments, discussions and workshops over a period of 6 months. The second author administered the module brief and organization of studio sessions. A total of $300 \mathrm{~h}$ of individual and groups discussions with 10 students were recorded in addition to 3 days of student reviews (each lasting $90 \mathrm{~min}$ ). In addition narrative methods included use of open ended interviews with 4 members of staff. Discussions with staff focused on the generation of studio briefs and views on applicability of environmental thinking in design projects. The members of staff all taught in the programme (BEng Architecture and Environmental engineering course) but did not always participate in the teaching of the module directly.

The authors as well as participant staff all have a background in the architecture and engineering domain. In addition to engaging through an immersive ethnographic journey, the researchers also developed an understanding of students' engagement through examining documentary evidence, module guides and programme specifications over time. Throughout the observations (across four phases) the first author sketched whilst talking and observing students' discussions to work through their ideas and explore their practices, processes and approaches to interpreting the brief in design (see Fig. 1).

Students (a total of 10) were given a project to examine a large site in the centre of Bristol which included an existing building. The key task for students was to reconsider/ reimagine the site including the regeneration of the existing building to highly ambitious energy efficient standards. Other than asking the students to allow for a large flexible space/auditorium that could accommodate 200 people, students had complete freedom to develop their site in terms of use/function and environmental strategy. The underlying principles of the project were fully developed proposals in terms of an architectural response in accordance with RIBA Part 1 prescription criteria as well as environmental engineering designs in accordance with CIBSE BEng requirements.

\section{Data analysis}

The data was compiled into a data bank and analysed thematically looking for key themes related to stages of students' responses and resolution of the design brief. Initially descriptive categories emerged related to how students responded and developed their project briefs including: Individual inspiration, Places, Urban motivation and Personal 


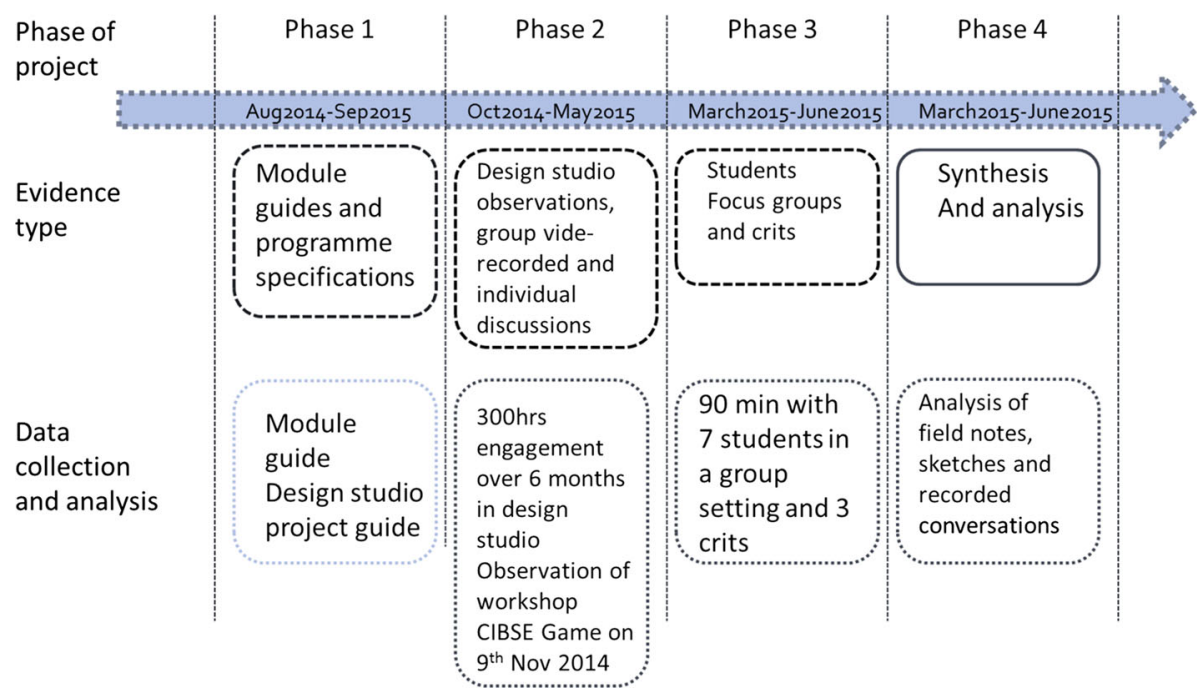

Fig. 1 Data collection and analysis phases

motivation. In the second phase, the initial descriptive categories were further analysed and re-coded based on key stages of design development to include subthemes (see Fig. 2). The subthemes were then further analysed to regroup into key thematic categories: Converging, Combining and Crystalizing.

\begin{tabular}{|c|c|c|c|}
\hline Key themes & $\begin{array}{l}\text { Stage } 1 \text { key } \\
\text { characteristics and } \\
\text { activities }\end{array}$ & $\begin{array}{l}\text { Stage } 2 \text { key } \\
\text { characteristics and } \\
\text { activities }\end{array}$ & $\begin{array}{l}\text { Stage } 3 \text { key } \\
\text { characteristics and } \\
\text { activities }\end{array}$ \\
\hline $\begin{array}{l}\text { Individual } \\
\text { inspiration }\end{array}$ & $\begin{array}{l}\text { Supporting, Enhancing } \\
\text { (community driven) }\end{array}$ & $\begin{array}{l}\text { Enabling } \\
\text { (individual focused) }\end{array}$ & $\begin{array}{l}\text { Keeping } \\
\text { (individual emphasis) }\end{array}$ \\
\hline Places & $\begin{array}{l}\text { Establishing } \\
\text { (typology of community } \\
\text { place) }\end{array}$ & $\begin{array}{l}\text { Fixing } \\
\text { (to individual activity } \\
\text { focus) }\end{array}$ & $\begin{array}{l}\text { Configuring } \\
\text { (beyond place) }\end{array}$ \\
\hline $\begin{array}{l}\text { Urban } \\
\text { Motivation }\end{array}$ & $\begin{array}{l}\text { Extending } \\
\text { (use of community } \\
\text { space) }\end{array}$ & $\begin{array}{l}\text { Connecting } \\
\text { (to individual notion of } \\
\text { space) }\end{array}$ & $\begin{array}{l}\text { Abstracting } \\
\text { (thinking beyond the } \\
\text { physical place) }\end{array}$ \\
\hline $\begin{array}{l}\text { Personal } \\
\text { Motivation }\end{array}$ & $\begin{array}{l}\text { Personifying } \\
\text { (own life experiences) }\end{array}$ & $\begin{array}{l}\text { Networking } \\
\text { (group strands) }\end{array}$ & $\begin{array}{l}\text { Maintaining } \\
\text { (personal motivations) }\end{array}$ \\
\hline
\end{tabular}

Fig. 2 Data analysis key themes 


\section{Findings}

Researchers observed all key stages of students' group and individual design approaches and developments of the brief for the site. Within each phase, particular activities and thinking emerged centred on: converging, combining and crystalizing ideas about the brief, site use and eventual building appearance and function.

\section{Converging}

The initial phase (stage 1) included observing group discussions about the possible uses and function of the site in relation to Bristol. Within group discussions, students explored the wider site relationships and connections. Discussions were facilitated by a member of staff who did not teach full time in the studio whilst researchers observed and recorded through use of sketches and field notes. Students were found to group objects of place (routes to site, ways out of site, within the site) in relation to individual interpretations of 'what Bristol needs' through three areas of focus: usage, activity and motivations. For instance, students were asked to imagine possible site uses drawing on experiences (individual and group) of Bristol as well as learning on architecture urban theories and history. In addition, students were encouraged to discuss and debate future possibilities of site use based on learning within and out with the course to date. When discussing individual interventions students were found to converge on group thinking through supporting personal understandings of Bristol's needs as a city. Personal opinions were often justified through discussion of how the site would be 'enhanced' by applying a particular intervention (see Fig. 3).

With regards to possible activities the site could accommodate students similarly tended to converge on group thinking by supporting an individual's preference. For instance, one of the students advocated for greater cycling areas in Bristol arguing for the site to be a cycling 'hot spot' or club. The group recognised the individual's student's personal ambition and passion for cycling and encouraged the use.

He is mad about cycling...that would be great like a hive of cyclers...somewhere to

go in Bristol if you were into that (Student G)

Another student emphasised the need for reusing clothing and drawing on Bristol's reputation for the avant-garde suggesting the site could develop into a centre for 'sustainable fashion'. In each instance the group supported an individual's idea and discussed ways their particular proposal would enhance the site and add to Bristol's identity in some way.
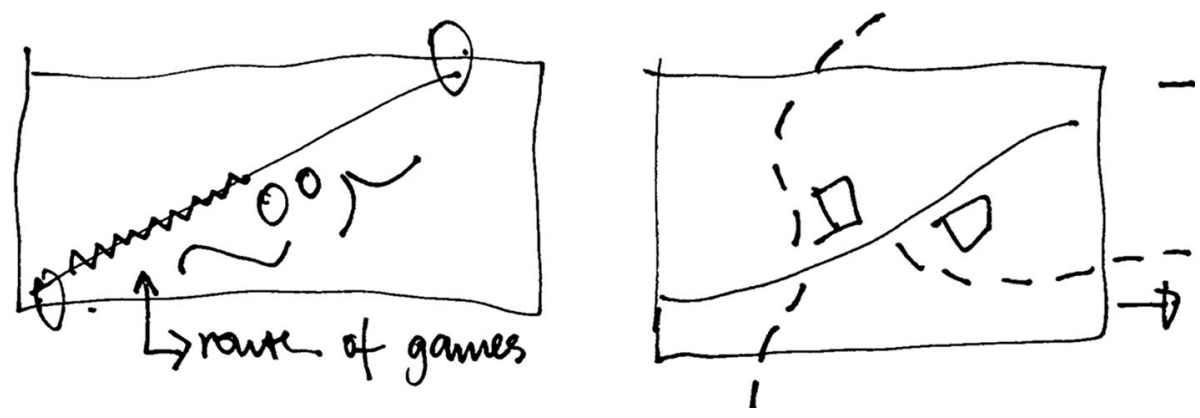

Fig. 3 Sketches showing group discussion on routes and uses of site 


\section{Combining}

In phase 2, students focused in on developing detailed individual interpretations of the brief. Throughout individual discussions with students which lasted between $45 \mathrm{~min}$ and $2 \mathrm{~h}$ researchers recorded through sketches and field notes students' approaches to brief development. During this phase most students focused primarily on personal hobbies, individual preferences and likes as a way of developing the brief with less attention devoted to the site overall. Students discussed their interpretations and views of (phase 1) group work where they were asked to assess how the project could address Bristol's needs. At this point during phase 2 they combine individual interests and Bristol needs to find common ground in devising their briefs.

One of the students discusses her interest and passion for books noting the practice of reading books is being lost and needs to be revived. She then goes on to highlight the lack of literature festivals in Bristol or spaces where writers and book enthusiast could meet.

I want to consider the revival of the book... what people need in Bristol is a place to write...to retreat (Student A)

Another student recalls a lack of health provision for very ill children in Bristol advocating for a place where children were supported and parents felt safe. The student often discusses Bristol health needs with a personal interest in providing special places for ill children to play.

Bristol needs this... a place where dying children can play...I want to create a place for support, play and feel...a homely feel... (Student JS)

Student $\mathrm{M}$ observes the unique music identity Bristol has that is often fleeting, unpreserved and overlooked.

I had a look at Bristol street art... and live music is not captured...is not preserved...I want to create an impression of music here... (Student $\mathrm{M}$ )

Throughout phase 2 students combine group thinking with individual motivations for the brief by advocating site uses based on personal interpretations and likes. In the case of the student motivated by cycling the site use was motivated by a personal ambition and passion. The student viewed cycling as an essential part of everyday life; in his view it was necessary for Bristol to have a site where cycling was a celebrated activity.

\section{Crystalizing}

In Phase 3 students' briefs and designs begin to crystalize whereby people and users are coalesced into the wider requirements for Bristol and personal motivations for the site (see Figs. 4, 5). The student (K) discusses the need for 'somewhere people can learn about foraging in Bristol' (see Fig. 4). In Fig. 4 sketches show discussions with a student about their view for need for urban foraging in Bristol... where activities of planting, tasting, cooking are linked to education in the wider Bristol realm.

Bristol has this culture of allotments...but people can't forage and pick plants... and I think Bristol could do with this (Student K)

Similarly, student (AD) discusses the need for 'approachable inclusive education in Bristol and his idea of a 'knowledge centre for all'. Throughout Phase 3, decisions and design approaches for the site and brief are regularly justified through initial brief decisions made 
at Phases 1 and 2. Students are found to hesitate applying any major brief change but are seen to regularly modify building shapes and appearance to improve designs and ensure further adherence to the brief (exceptions include student $M$ who departed little from original building shape and massing).

Figure 5 shows an example of a discussion with a student whereby the researcher sketches whilst talking to the student. Sketches are often shown to the student to initiate further observation and debate. The student (AD) discusses the need for "literature culture...somewhere where people can learn about how books are made...somewhere where they can write and read...sort of printing on demand... Bristol is viewed as a city that needs a knowledge market' (Fig. 6).

there is a lack of literature and arts culture in Bristol...we need printing, making and binding....all in Bristol (Student AD)

Within each phase of the development of design proposals students encounter specific activities (see Fig. 7). For instance, when combining students focus on activities of enhancing, extending, personifying and establishing the 'group' idea to a place and driving the brief activities. When converging, students emphasise activities of enabling, fixing, networking and connecting the 'group' or community idea of place to their individual conception of space. However, with such an overwhelming individual closeness to the generation of design brief students often overlook other specifically environmental aspects of a brief particularly at the early stages. Instead, they hone and adapt the brief largely in relation and in response to personal experience and preference. When crystalizing, students are seen to keep, abstract, configure and most importantly maintain that personal motivation and ambition of the brief interpretation. Although at later stages specifically when reminded in assessments, students do start to show evidence of brief departure it is often when the built forms are almost fully developed.
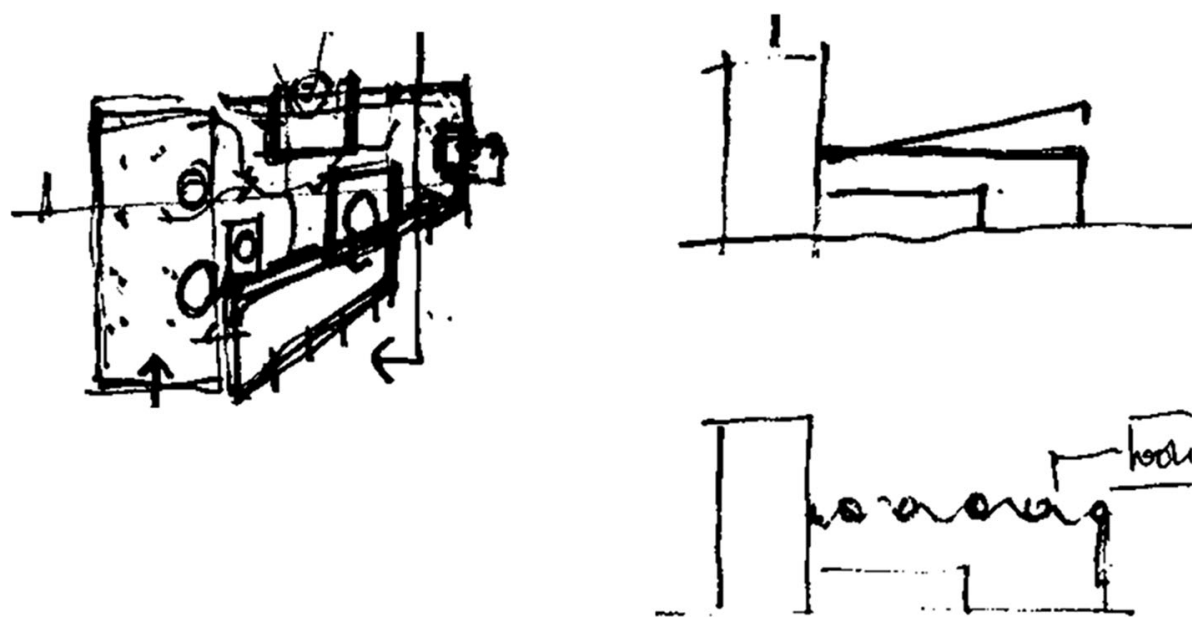

Fig. 4 Sketches showing individual discussion with student $\mathrm{K}$ 
Fig. 5 Sketches showing individual discussion with student AD

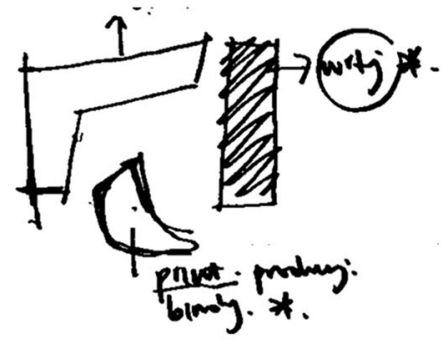

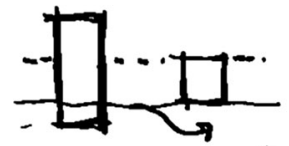

Aonam

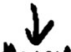
thume about forre rems:
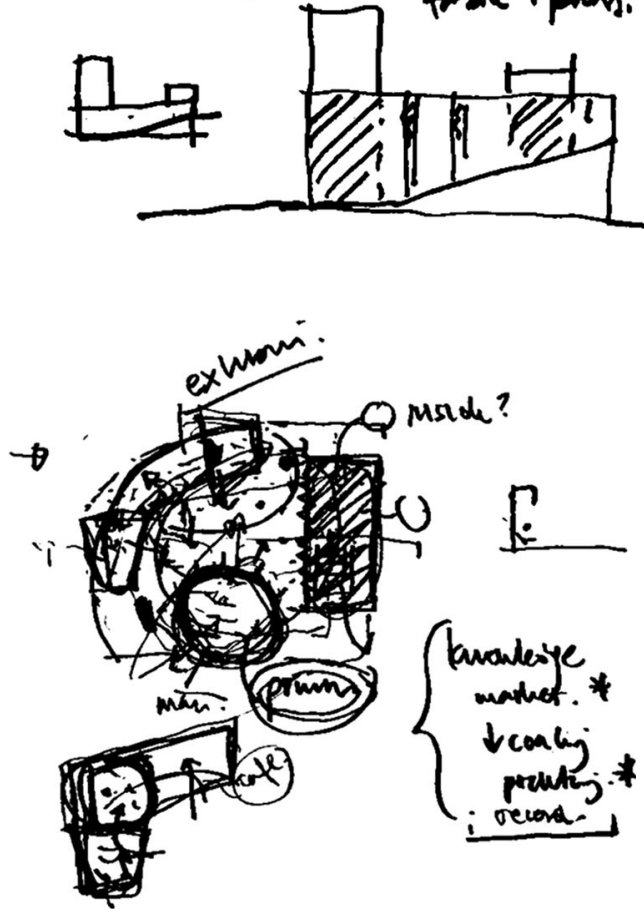

Fig. 6 Sketches showing individual discussion with student A

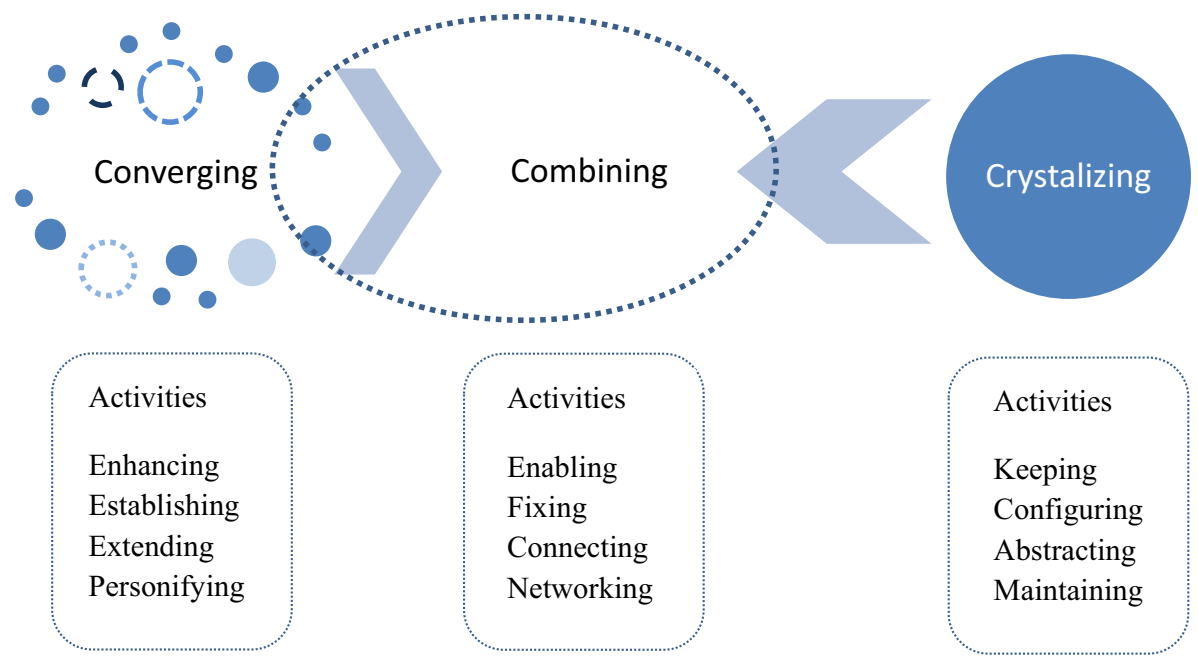

Fig. 7 Key mechanisms 


\section{Discussion and conclusion}

The journey of the research shows three phases that at times overlap and are not necessarily linear. The lack of a prescribed brief enables students to focus on the use of the site from a personal and wider city perspective through three mechanisms: converging, combining and crystalizing. Research has argued for less prescription in design studio brief development to enable greater environmental integration and application in design proposals (Altomonte 2009; Rutherford and Wilson 2006). There appears to be some consensus between scholars that a less prescriptive approach to design studio education would facilitate students' personal reflexivity and encourage individual 'voice' in their studio projects (Batterman et al. 2011; Iulo et al. 2013; Pan et al. 2012). However, there is a lack of research that examines the effects of a less prescriptive, student-led approach on students' experience, curriculum design or staff opinion. Furthermore, dominant discourse focuses on the positive outcomes associated with greater levels of flexibility in the design studio.

The study reported here shows that lack of brief prescription can often lead to brief dependence derived from personal experience, preference and likes often to the detriment of environmental consideration and application. In this study, students are found to engage profoundly with brief development engaging in detailed and critical discussion throughout. However, once they settle on a brief often derived from an individual ambition, flexibility in approach in design development is often hindered. The deep engagement with brief development for many students becomes a personal voyage (into highlighting importance of cycling, foraging or literature for instance) to the detriment to fully developing and engaging with environmental aspects of design.

Despite growing concern regarding the content and mode of delivery regarding UK architectural education overall and sustainability concerns specifically (The Oxford Conference 2008), few studies have examined the ways particular non-prescriptive approaches have been interpreted by students. In addition, a dearth of research has analysed how particular areas of the syllabus such as sustainability have been included by different institutions within design briefs specifically. Detailed analysis of both how skills, knowledge, abilities and awareness have been interpreted in architectural education regarding sustainability content as well as a wider consideration of the effects of incorporating specific approaches such as non-prescriptive briefs or transdisciplinary methods are needed.

Future work could examine views and concerns from students across institutions and between different built environment curricula within courses that set non-prescriptive briefs within transdisciplinary environments. Also, further research could delve deeper into understanding how increased levels of brief flexibility impact on both the student and educator experience. The study reported here focused on student experience for instance; however, observations note a need to also understand educator experience. Our research points to some interesting observations and potentially innovative visual research methods including the use of sketching to inform and record discussions with students. Although visual research methods are growing in use within design education studies, they often examine and record participants' work. In this study researchers apply visual methods such as sketching to observe, record and engage in discussion. Further work is required to develop methods and recording of sketching as a way of ethnographically observing design education experiences. 
Future work could also gain a greater understanding of different levels of perceptions and perhaps in depth discussion of formal applications of transdisciplinary and polymorphic education in various design disciplines.

Acknowledgments The authors would like to thank Emma Griffin for her assistance in the paper development as well as all the students and staff who participated in this study.

Open Access This article is distributed under the terms of the Creative Commons Attribution 4.0 International License (http://creativecommons.org/licenses/by/4.0/), which permits unrestricted use, distribution, and reproduction in any medium, provided you give appropriate credit to the original author(s) and the source, provide a link to the Creative Commons license, and indicate if changes were made.

\section{References}

Altomonte, S. (2009). Environmental education for sustainable architecture. Review of European Studies, 1.2 .

Altomonte, S., Rutherford, P., \& Wilson, R. (2012). Mapping the way forward: Education for sustainability in architecture and urban design. Corporate Social Responsibility and Environmental Management, 21(3), 143-154.

Austerlitz, N. (2007). The internal point of view: Studying design students' emotional experience in the studio via phenomenography and ethnography. Art, Design \& Communication in Higher Education, 5(3), 165-177.

Batterman, S. A., Martins, A. G., Antunes, C. H., Freire, F., \& da Silva, M. G. (2011). Development and application of competencies for graduate programs in energy and sustainability. Journal of Professional Issues in Engineering Education \& Practice, 137(4), 198-207.

Coleman, N. (2010). The limits of professional architectural education. International Journal of Art \& Design Education, 29(2), 200-212.

Cotgrave, A., \& Alkhaddar, R. (2006). Greening the curricula within construction programmes. Journal of Education in the Built Environment, 1(1), 3-29.

Cotgrave, A. J., \& Kokkarinen, N. (2011). Promoting sustainability literacy in construction students. Structural Survey, 29(3), 197-212.

Cross, N. (2011). Design thinking: Understanding how designers think and work. Oxford, New York: Berg.

Curry, T. (2014). A theoretical basis for recommending the use of design methodologies as teaching strategies in the design studio. Design Studies, 35(6), 632-646.

Goldschmidt, G., \& Rodgers, P. A. (2013). The design thinking approaches of three different groups of designers based on self-reports. Design Studies, 34(4), 454-471.

Iulo, L. D., Gorby, C., Poerschke, U., Kalisperis, L. N., \& Woollen, M. (2013). Environmentally conscious design-educating future architects. International Journal of Sustainability in Higher Education, 14(4), 434-448.

Lawson, B., \& Dorst, K. (2013). Design expertise. Abingdon: Routledge.

Murray, P., \& Cotgrave, A. (2007). Sustainability literacy: The future paradigm fo construction education? Structural Survey, 25(1), 7-23.

O'Rafferty, S., Curtis, H., \& O'Connor, F. (2014). Mainstreaming sustainability in design education-A capacity building framework. International Journal of Sustainability in Higher Education, 15(2), 169-187.

Pan, W., Murray, P., Cotton, D., \& Garmston, H. (2012). Integrating research-informed teaching into sustainable construction education. Journal of Education in the Built Environment, 7(1), 94-117.

Paton, B., \& Dorst, K. (2011). Briefing and reframing: A situated practice. Design Studies, 32(6), 573-587.

Peel, D. (2010). Collaborative professionalism. Journal of Education in the Built Environment, 5(2), 1-3.

Peel, D. (2012). Pushing the envelope of built environment education. Journal of Education in the Built Environment, 7(1), 1-7.

RIBA. (2003). Tomorrow's architect: RIBA outline syllabus for the validation of courses, programmes and examinations in architecture. Newcastle upon Tyne: RIBA Enterprises.

Rutherford, P., \& Wilson, R. (2006). Educating environmental awareness: Creativity in integrated environmental design teaching. In Architecture (Ed.), Challenges for architectural science in changing climates. City: ANZAScA: Adelaide. 
Savic, M., \& Kashef, M. (2013). Learning outcomes in affective domain within contemporary architectural curricula. International Journal of Technology and Design Education, 23(4), 987-1004.

Schön, D. A. (1988). Toward a marriage of artistry \& applied science in the architectural design studio. Journal of Architectural Education, 41(4), 4-10.

The Oxford Conference. (2008). A re-evaluation of education in architecture. 